\title{
Cultural adaptation and assessment of the reliability of the Special Needs Kids Questionnaire for the Brazilian context
}

\author{
Adaptação cultural e avaliação da fidedignidade do Special \\ Needs Kids Questionnaire para o contexto brasileiro \\ Adaptación cultural y evaluación de la fidedignidad del Cuestionario \\ Infantil de Necesidades Especiales para el contexto brasileño
}

How to cite this article:

Ferreira LTL, Parra PC, Okido ACC. Cultural adaptation and assessment of the reliability of the Special Needs Kids Questionnaire for the Brazilian context. Rev Gaúcha Enferm. 2021;42:e20200488 doi: https://doi.org/10.1590/19831447.2021.20200488 aniversidade Federal de São Carlos (UFSCar), Centro de Ciências Biológicas e da Saúde, Programa de Pós-graduação em Enfermagem. São Carlos, São Paulo, Brasil.

- Universidade Federal de São Carlos (UFSCar), Centro de Ciências Biológicas e da Saúde, Curso de Enfermagem. São Carlos, São Paulo, Brasil.

\section{Larissa Tassim Luciano Ferreira ${ }^{a}$ Patrícia Casale Parrab Aline Cristiane Cavicchioli Okido ${ }^{a}$}

\section{ABSTRACT}

Objective: To carry out the cultural adaptation of the Special Needs Kids Questionnaire into Brazilian Portuguese and assess its reliability.

Methods: Methodological study conducted between September 2019 and June 2020 from the stages of translation, backtranslation, content validation, semantic validation and pilot test. ContentValidation Index, Cronbach's Alpha Coefficient and Intraclass Correlation Coefficient were calculated.

Results: After the second round, the adapted version had a Content Validation Index greater than 0.80 in all items and was considered understandable by the mothers. The pilot test included 89 mothers of children born prematurely from the Neonatal Intensive Care Unit in the test and 44 in the retest. All items had Cronbach's Alpha greater than 0.70 . Of the 20 items, 15 showed moderate reliability, three high and two weak.

Conclusion: The instrument proved to be reliable and has the potential to identify the fragmentation and discontinuity of the care received.

Keywords: Infant, newborn. Continuity of patient care. Validation study. Child. Pediatric nursing.

\section{RESUMO}

Objetivo: Realizar a adaptação cultural do Special Needs Kids Questionnaire para o português do Brasil e avaliar sua fidedignidade. Métodos: Estudo metodológico realizado entre setembro de 2019 e junho de 2020 a partir das etapas de tradução, retrotradução, validação de conteúdo, validação semântica e teste piloto. |Foi calculado Índice de Validação de Conteúdo, Coeficiente Alpha de Cronbach e Coeficiente de Correlação Intraclasse.

Resultados: Após segunda rodada, a versão adaptada apresentou Índice de Validação de Conteúdo superior a 0,80 em todos os itens e foi considerada compreensível pelas mães. 0 teste piloto contou com 89 mães de crianças nascidas prematuras egressas da Unidade de Terapia Intensiva Neonatal no teste e 44 no reteste. Todos os itens apresentaram Alpha de Cronbach superior a 0,70. Dos 20 itens, 15 demonstraram moderada confiabilidade, três alta e dois fraca.

Conclusão: Instrumento mostrou-se fidedigno e tem potencial para identificar a fragmentação e descontinuidade do cuidado recebido.

Palavras-chave: Recém-nascido prematuro. Continuidade da assistência ao paciente. Estudo de validação. Criança. Enfermagem pediátrica.

\section{RESUMEN}

Objetivo: Realizar la adaptación cultural del Cuestionario para niños con necesidades especiales al portugués brasileño y evaluar su fiabilidad.

Métodos: Estudio metodológico realizado entre septiembre de 2019 y junio de 2020 a partir de las etapas de traducción, retrotraducción, validación de contenido, validación semántica y prueba piloto. Se calcularon el índice de validación de contenido, el coeficiente alfa de Cronbach y el coeficiente de correlación intraclase.

Resultados: Después de la segunda ronda, la versión adaptada tuvo un Índice de Validación de Contenido superior a 0,80 en todos los ítems y fue considerada comprensible por las madres. La prueba piloto incluyó a 89 madres de niños nacidos prematuramente de la Unidad de Cuidados Intensivos Neonatales en la prueba y 44 en la reprueba. Todos los ítems tenían un Alfa de Cronbach superior a 0,70. De los 20 ítems, 15 mostraron confiabilidad moderada, tres alta y dos débil.

Conclusión: El instrumento demostró ser confiable y tiene potencial para identificar la fragmentación y discontinuidad de la atención recibida.

Palabras clave: Recien nacido prematuro. Continuidad de la atención al paciente. Estudio de validación. Niño. Enfermería pediátrica. 


\section{口INTRODUCTION}

Children with special health care needs (CSHCN) demand continuous care of a permanent nature and need more attention from health and social services than other children in the same age group ${ }^{(1)}$. It is estimated that in the United States $15.1 \%$ of children have some special health care need, totaling approximately 11.2 million children and adolescents in this condition ${ }^{(2)}$. In Brazil, there are no national estimates for children under these conditions ${ }^{(2)}$.

Premature newborns, especially those discharged from neonatal intensive care, can be considered a specific subgroup of $\mathrm{CSHCN}^{(3)}$, as they have higher rates of long-term morbidity, such as neurological and developmental disabilities, compared to full-term babies ${ }^{(4)}$. The main morbidities generally associated with prematurity are: cerebral palsy, visual alterations and blindness, hearing deficits, high respiratory morbidity, among others ${ }^{(5)}$. Approximately $11.1 \%$ of newborns worldwide are born prematurely, which is equivalent to about 15 million premature births annually ${ }^{(4,6-7)}$.

As for the care that should be given to premature children after hospital discharge, demands related to the administration of drugs and enteral diet deserve mention, in addition to the need for constant medical monitoring ${ }^{(6)}$. In some cases, preterm infants may also need a device to compensate for the loss of a vital function such as tracheostomy, mechanical ventilation and gastrostomy ${ }^{(6)}$.

According to a qualitative research with six families of children discharged from the neonatal intensive care unit, the birth of a preterm newborn (PTNB) and in need of intensive care generates frustration, disappointment, anxiety and lack of confidence in the capacity to properly care of the baby ${ }^{(8)}$. In this regard, an international investigation that explored the experiences of mothers of extremely preterm babies during the transition home reported that mothers were in a state of permanent surveillance due to lack of preparation and fear ${ }^{(7)}$.

Due to the potential frailty of these children and the specific demands of care, continuity of care after hospital discharge is essentia $\left.\right|^{(9)}$, especially because this can minimize injuries and hospital readmissions, as well as to strengthen the family's adaptation process to care ${ }^{(5)}$. On the other hand, discontinuity of care can put the child's health at risk due to the need for constant hospitalizations and the family's difficulty in having autonomy and security to manage prematurity ${ }^{(5)}$.

However, the integration between health professionals involved in the proper coordination of care for preterm infants is limited ${ }^{(10)}$. Network communication is inadequate and it is up to the caregiver to pass on the information to the various professionals involved in the care process, which undermines the continuity of care ${ }^{(11)}$. In addition, primary care services have not successfully met the demands of this clientele, which results in family dissatisfaction and strengthens the search for prompt hospital care as an entry point to the health system ${ }^{(8)}$. Given the fragility and lack of coordination of the health care network in the care of children with special health needs, it is essential to create means of continuous assessment of care in health services for this public, from PHC to high complexity health services ${ }^{(2)}$.

Thus, researchers from the University of Bologna, Italy, conducted a qualitative study that explored the experiences and perceptions of parents of premature infants regarding the continuity of care from hospitalization until the first months after discharge to home ${ }^{(10)}$. The results of this study supported the elaboration of the Special Needs Kids Questionnaire (SpeNK-Q), an instrument whose main objective is to measure the parents' perspective on the continuity of care for children with special health needs ${ }^{(3)}$. This instrument is available in Italian, English and Chinese ${ }^{(3,12)}$.

In view of the aforementioned, the social and academic relevance of this study is justified, as it proposes to carry out the cultural adaptation and evaluation of the reliability of an instrument capable of measuring the continuity of care for children with special health needs, in particular preterm newborns discharged from the Neonatal Intensive Care (NICU). It is also necessary to highlight the originality of the study, since there is no instrument for this purpose in Brazil. Thus, the present study aims to carry out the cultural adaptation of the Special Needs Kids Questionnaire (SpeNK-Q) to Brazilian Portuguese and assess its reliability.

\section{$\square$ METHOD}

This is a methodological study carried out between January and June 2020. The steps of the cultural adaptation followed the recommendations of the DISABKIDS ${ }^{\circledR}$ Group, namely: translation, back-translation, content validation, semantic validation and pilot test ${ }^{(13)}$. The researchers who developed the original instrument, as well as the person responsible for the DISABKIDS ${ }^{\oplus}$ Group in Brazil, authorized the development of this study.

The SpeNK-Q contains 20 items subdivided into five factors. Factor 1 corresponds to "information continuity", that is, the consistency of information shared between health professionals and the parents'feeling of being "well known"versus "abandoned" by health professionals (items 8,12,13,14,15, 18 and 20). Factor 2 refers to "coordination of care" and assesses how well the health professional responsible for most of the child's care knows their health care needs, maintains regular contact with the family and other professionals (items 4,5, 6 and 7). Factor 3 assesses "relational continuity", that is, the 
experience of an ongoing therapeutic relationship between the child, family and health professional (items 1,2 and 3). Factor 4, called "family support", concerns the information provided to the family about the child's conditions, to take care of the child at home, deal with minor complications and the possibility of getting answers or advice quickly when necessary (items 9.16,17 and 19). Finally, Factor 5 "Information about the care plan"evaluates the explanations given to the family about the care provided and planned for the child, such as treatments and exams (items 10 and 11$)^{(3)}$.

The SpeNK-Q is answered with the use of a Likert-type scale. To interpret the results, the percentages of responses for each item are calculated separately. The instrument does not allow measuring a final total score or even a factor ${ }^{(3)}$. Thus, items 1 to 7 measure the agreement regarding their respective statements: 1 (completely disagree), 2 (disagree), 3 (undecided), 4 (agree) and 5 (completely agree). In this case, options 4 and 5 represent a positive assessment and options 1 and 2 a negative assessment, while option 3 represents a midpoint of neutrality.

For the other items of SpeNK-Q, the possible responses indicate the frequency with which each situation occurred: 1 (never or almost never), 2 (seldom), 3 (sometimes), 4 (often) and 5 (always or almost always). However, interpretation depends on the situation presented in each item, that is, for those items that present a situation considered adequate to ensure continuity of care, answer options 4 and 5 will indicate a positive perception (items 9,10,11,12,16,17, 18 and 19). As for the items that represent an inadequate situation (items 8,12,13,14, 15 and 20), answer options 1 and 2 represent a positive perception about the continuity of care ${ }^{(3)}$.

The specificities of each methodological step are outlined in Figure 1 and described below:

\section{Translation and back-translation}

Two independent translators, native Portuguese speakers and with experience in the language and culture of the original instrument performed the translation. After analyzing the two versions produced, a consensual translation was obtained, which was back-translated into Italian, the instrument's original language.

\section{Content validation}

For content validation, an expert committee composed of ten professionals was constituted. The criteria for choosing this committee were as follows: professional with expertise in the area of neonatal and/or pediatric nursing, with academic and/or care experience of at least five years. It should be stressed that the recruitment of experts was carried out through consultations on the curriculum Lattes Platform. The expert committee assessed the translated version for conceptual equivalence, item equivalence, operational equivalence and semantic equivalence. A Likerttype scale with the responses: disagree, undecided and agree was used. For analysis, the Content Validation Index was computed for the 20 items of the instrument, and this was considered validated if a value equal to or greater than 0.80 was obtained.

\section{Semantic validation}

To verify the acceptability and comprehensibility of the instrument, 24 mothers (and/or guardians) over 18 years old, of premature newborns discharged from a private Neonatal Intensive Care Unit located in the inland of the state of São Paulo, were recruited. The choice of the NICU was intentional as one of the researchers was part of the team at this unit. The referred NICU was opened in 2015, with eight beds and an average occupancy rate of $50 \%$.

This step was performed at the participants' homes, and the respondents made a general analysis of the instrument and a specific analysis of the items comprised. Initially, the SpeNK-Q was applied (approximately 20 minutes of application) and then the participants were asked about the comprehensibility and clarity of the items and whether there was any difficulty in answering them (general analysis). For the specific analysis, the 20 items were subdivided into four subsets (five items in each subset) and each subset of items was evaluated by six mothers, three of whom completed high school and three had completed higher education. In the specific analysis, the participants explained the items in their own words, allowing the researcher to assess the degree of understanding and identify words or expressions that could give greater clarity to the instrument. The specific analysis was audio recorded.

Regarding the number of participants, the recommendations of the DISABKIDS ${ }^{\circledR}$ Group were observed, which recommends that each item subset be evaluated by three subjects from two different age groups ${ }^{(13)}$. However, as the participants were adults, their educational level was considered instead of age, similar to what was proposed in a recent study ${ }^{(14)}$. 


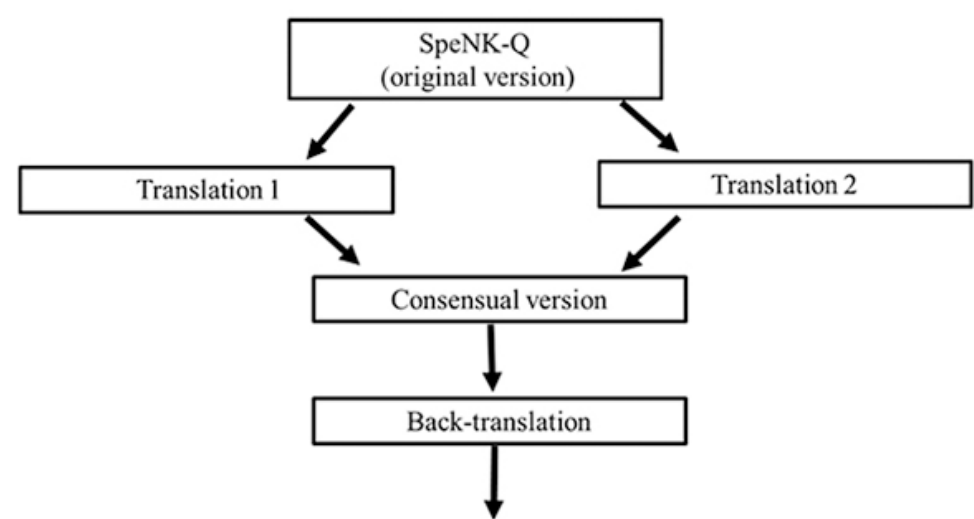

Content validation

10 experts assessed conceptual, operational, semantic and item equivalence.

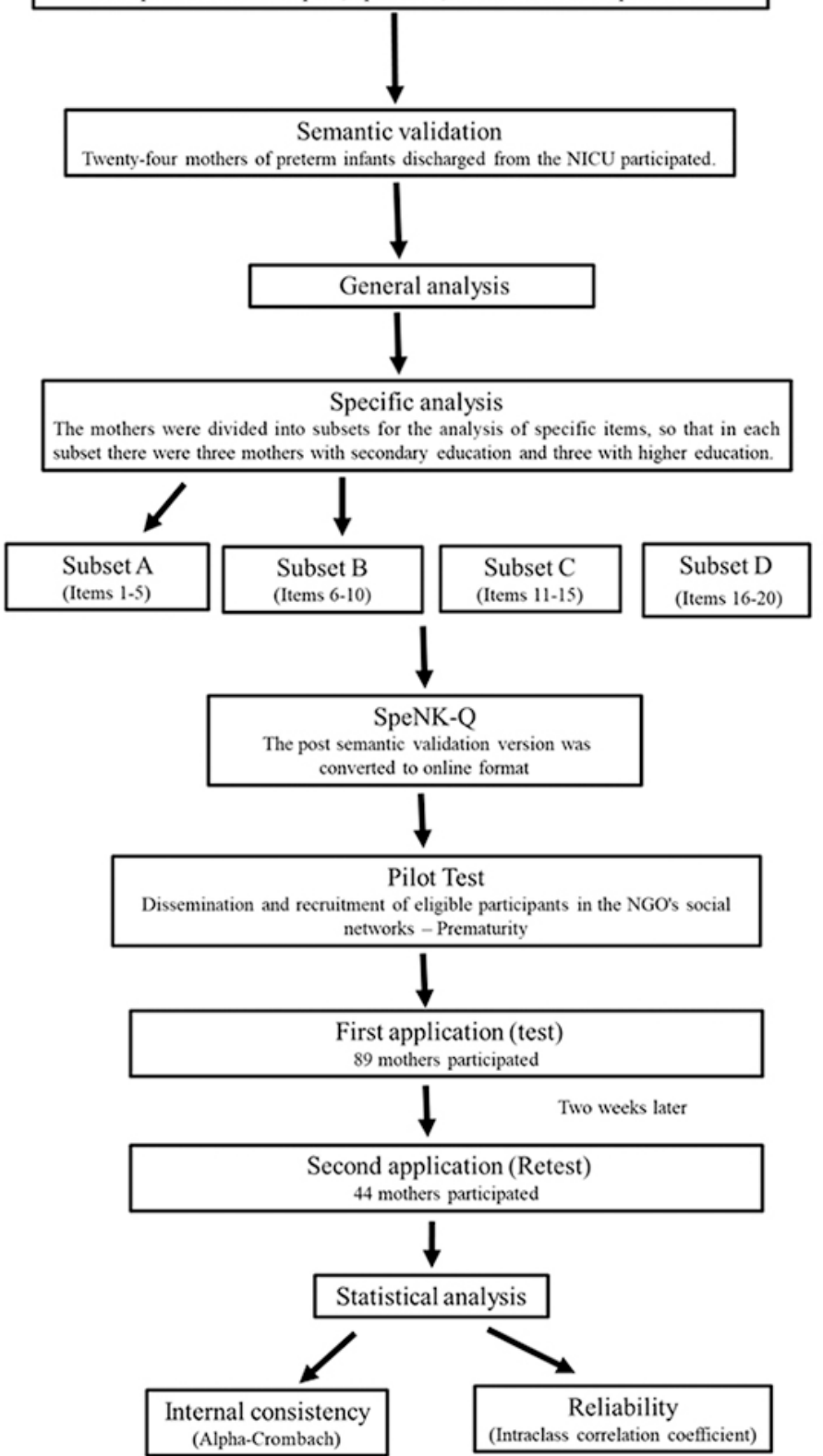

Figure 1 - Flowchart of the phases of cultural adaptation of SpeNK-Q to Brazilian Portuguese, 2019/2020 Source: The authors, 2020. 


\section{Pilot test}

To assess the reliability of the adapted version of the SpeNK-Q, the stage called pilot test was developed. Given the restrictions on social contact imposed by the COVID-19 pandemic, data collection was remote. The adapted version of the SpeNK-Q, the sociodemographic characterization instrument, as well as the Informed Consent Form (ICF) were converted to online format using Google Forms. The eligibility criteria of the participants were mothers and/or guardians over 18 years old of preterm babies discharged from the Neonatal Intensive Care Unit.

To recruit participants, a partnership was established with the Brazilian Association of Parents, Families, Friends and Caregivers of Preterm Babies - NGO Prematuridade.com, which announced the invitation to participate in the survey on its social networks. It is a non-profit organization founded in 2014 that is dedicated to the prevention of premature births, continuing education for health professionals and the support to public policies in favor of the interests of families of preterm babies. It is headquartered in Porto Alegre, Rio Grande do Sul, but it has support centers throughout the country. Currently, NGO Prematuridade.com has more than 30 thousand followers on its social networks.

A link was available in the invitation to participate in the study. By clicking on this link, the participant was directed to the Google Forms platform. The TCLE was made available on the form's home page and only after expressing their agreement, the participants had access to the data collection instruments. The average time to respond to the online form was 20 minutes.

Two weeks later, a new link was sent to participants in order to reapply the adapted version of SpeNK-Q, a method known as test-retest. This strategy makes it possible to assess the ability of the adapted version of the SpeNK-Q to produce the same or similar results in the two application moments. The organization and analysis of the results of this step occurred as follows: the form responses were automatically entered in an Excel spreadsheet and later, the database was exported to The SAS System for Windows (Statistical Analysis System), version 9.2, in which analyzes were performed. To describe the profile of the participants, absolute frequency (n) and percentage (\%) tables were organized for categorical variables, and for numerical variables, mean, standard deviation, minimum and maximum values, median and quartiles were calculated.

For the assessment of the internal consistency between the items, Cronbach's Alpha Coefficient was calculated, with values greater than 0.70 being considered valid. To compare the distribution of responses in each of the 20 SpeNK-Q items in the test and retest, the Intraclass Correlation Coefficient was calculated, which varies from 0 (lack of reliability) to 1.0 (perfect reliability). To assess the ICC, the following criteria presented by the North American biostatistics professor Joseph L. Fleiss were used high reliability 1 to 0.75 ; moderate 0.4 to 0.74 and weak $<0.4^{(15)}$.

Considering the involvement of human beings in the research, the project was submitted to the Research Ethics Committee of the University to which the researchers were attached in compliance with Resolution 466/2012 of the National Research Ethics Commission of the National Health Council. Project registered with CAAE 89462618.9.0000.5504 and approved under protocol no 2,697,212.

\section{RESULTS}

As described in the method, after the translation and back-translation step, the SpeNK-Q was submitted to content validation by ten experts. All were female, with a mean age of 34.8 years and the average time elapsed since graduation was 10.4 years. Regarding the degrees of the participants, five (50\%) were masters, three (30\%) doctors and two (20\%) had postdoctoral degrees. Seven (70\%) worked as professors and three (30\%) as nurses in direct patient care. In the first round, the CVI for the "semantic equivalence" criterion was lower than the limit established in ten items $(1,4,5,6,8,9,13,15,17$ and 20). The other criteria reached indexes above 0.80 in all items.

The ten items were revised until expert consensus was reached. Some adjustments made included replacement of the term "neighborhood health service" by "health unit" and the term "pediatrician" for "doctor/health professional". According to the experts, in Brazil, and especially in the Family Health Strategy program, doctors who treat children are not always pediatricians. The experts also suggested that the term "others", present in several items, be clearly explained, and it was then replaced by "other health professionals". Likewise, the expression "the person who was visiting my child" was changed to "health professional who performed a home visit".

In the semantic validation step, 24 mothers participated, of which 12 (50\%) had completed high school and 12 (50\%) had completed higher education, as recommended in the method. Regarding the age group, 08 (34\%) mothers were between 20 and 30 years old, the others were over 30 years old. Most 23 (95\%) said they had a partner and 14 (58\%) had other children besides the premature newborn. As for occupation, 20 (83.4\%) reported formal paid work, 4 (16.6\%) chose to leave their jobs after the birth of their children.

Regarding the characterization of the 29 preterm newborns (PTNB) of the 24 participating mothers, it should be noted that 10 (35\%) were twins, 17 (58\%) were female and 19 (66\%) were born between 30 and 33 weeks. As for the length of stay in the NICU, 2 (7\%) remained hospitalized for 
a period of less than 7 days, 11 (38\%) between 7 and 30 days, 9 (31\%) between 31 and 60 days and 7 (24\%) above 60 days. Two PTNBs used life-sustaining technological devices (gastrostomy and tracheostomy with mechanical ventilation - Bilevel Positive Airway Pressure/BIPAP).

Regarding the general impression of the SpeNK-Q, most participants 21 (88\%) rated it as "very good". As for the difficulty of the questions, 16 (66\%) mothers reported that all were easy and eight (34\%) found some questions difficult. Regarding possible difficulties in using the response options, 21 (88\%) said they had no difficulty and three (12\%) said they had experienced some difficulty. Regarding the relevance of the questions, only one mother chose the response option "sometimes it's important", the other 23 (96\%) considered it "very important". No differences were observed in the distribution of responses between mothers with secondary education and mothers with higher education.

The SpeNK-Q specific assessment was answered according to the four subsets of items detailed in the method. The first aspect evaluated concerned the importance attributed to each item and, for mothers with high school education, no item was considered as unimportant for the child's situation. In contrast, items $12,13,14$ and 15 with questions about home visits carried out by health professionals for the preterm newborns and their families were considered "not important"for mothers with higher education.

Regarding the analysis of the distribution of the responses of mothers with high school education according to the difficulty encountered and the correct explanation of the SpeNK-Q items, it should be noted that difficulty in understanding items 8 and 12 was reported. However, the participants were able to correctly explain what had been asked. The opposite occurred with items $13,14,15$ and 19 when the mothers said they had no difficulty in understanding the questions, but they were wrongly explained by two mothers who did not understand them. Regarding the responses of mothers with higher education, one participant stated she found it difficult to understand items 8 and 10, but explained them correctly; five items were not explained correctly although the referred participant said she did not find it difficult to understand them.

In view of the results of the semantic validation, adjustments were made to the instrument to make it more understandable. Thus, for items related to home visits (12, 13 and 15), the option "not applicable" was added in order to discourage inadequate responses due to lack of access to this care practice. It is noteworthy that it was only possible to add a new answer option because of the way in which the answers are calculated i.e the lack of a final total score, as detailed in the method.

In the first application of the pilot test there were 89 participants and in the retest stage, 44 returned. All participants were mothers. Regarding the age of the participants, the average age was 32.49 years, minimum age 20 and maximum age 43. Table 1 describes the absolute frequency ( $n$ ) and percentage (\%) for the other variables to characterize the 89 participating mothers.

Table 1 - Distribution of participants ( $n=89$ ) according to variables education, place of origin, occupation, marital status, other children and health insurance plan. São Carlos/SP, 2020

\section{Variables $\quad n(\%)$}

\section{Education}

Secondary school

$20(22.47)$

Higher education

69 (77.53)

\section{Place of origin}

Southern Region of Brazil

$21(23.60)$

Southeast Region of Brazil

$49(55.06)$

Central-West Region of Brazil

Northeast Region of Brazil

$10(11.24)$

Northern Region of Brazil

Outside Brazil/Abroad

\section{Occupation}

$\begin{array}{lc}\text { Household tasks } & 13(14.61) \\ \text { Informal work } & 3(3.37) \\ \text { Formal work } & 45(50.56) \\ \text { Self-employed } & 19(21.35) \\ \text { Unemployed } & 9(10.11)\end{array}$

\section{Marital status}

With a partner

$80(89.89)$

Without a partner

$9(10.11)$

\section{Other children}

Yes

$33(37.08)$

No

$56(62.92)$

\section{Health insurance plan}

Yes

49 (55.06)

Health insurance plan + SUS

24 (26.97)

No

$16(17.98)$

Source: Research data, 2020 
Table 2 presents the descriptive statistics of the numerical variables concerning the 95 premature children of the 89 mothers (participants) discharged from the NICU.

Table 3 shows the internal consistency coefficient (Cronbach's a) of the respective SpeNK-Q factors, indicating high reliability $(>0.70)$ in all factors.

To compare the distribution of responses in each of the 20 SpeNK-Q items in the test and retest, ICC was calculated, as shown in table 4 . In the analysis, it can be seen that 15 items showed moderate reliability in the responses, three achieved high reliability and two items (9 and 12) showed poor test-retest reliability.

Finally, it should be noted that 74 (83\%) participants of the test and 38 (86\%) participants of the retest chose the answer option "not applicable" for items 12, 13 and 15 concerning home visits.

Table 2 - Distribution of children discharged from the NICU ( $n=95)$ according to the variables current age, gestational age and birth weight, length of stay in the NICU and number of readmissions. São Carlos/SP, 2020

\begin{tabular}{lccccc} 
Variables & Mean & Standard deviation & Minimum & Median & Maximum \\
Current age (years) & 1.48 & 1.74 & 0.00 & 1.00 & 8.00 \\
Gestational age at birth (weeks) & 30.43 & 2.78 & 23.00 & 30.00 & 35.00 \\
Birth weight (grams) & 1363.7 & 535.26 & 415.00 & 1330.00 & 2550.00 \\
Length of stay (days) & 51 & 40 & 3 & 42 & 180 \\
Number of readmissions & 0.51 & 1.26 & 0.00 & 0.00 & 10.00 \\
\hline
\end{tabular}

Source: Research data, 2020

Table 3 - Internal Consistency Coefficient (Cronbach's a) according to the five factors of the adapted SpeNK-Q version. São Carlos/SP, 2020

\begin{tabular}{ccc} 
Factor & Number of items & Cronbach's a \\
Factor 1 & 7 & 0.748 \\
Factor 2 & 4 & 0.790 \\
Factor 3 & 3 & 0.789 \\
Factor 4 & 4 & 0.803 \\
Factor 5 & 2 & 0.854 \\
\hline
\end{tabular}

Source: Research data, 2020.

Table 4 - Intraclass correlation coefficient (ICC) between the answers for each of the 20 SpeNK-Q items in the test and retest. São Carlos/SP, 2020

\section{SpeNK-Q items}

ICC (IC 95\%)

\section{About the doctor who takes care of your child}

1. The doctor knows my child's health history.

$0.687(0.491 ; 0.816)$

2. The doctor accepts my opinion regarding my child's health.

$0.658(0.450 ; 0.798)$ 
Table 4 - Cont.

3. I feel comfortable talking to the doctor about any problems related to my child's health.

$0.647(0.437 ; 0.791)$

\section{About the health professional who takes care of all or almost all of the child's health problems}

4. This health professional knows all of my child's health problems.

$0.680(0.481 ; 0.812)$

5. This health professional is always informed about the care provided by other healthcare professionals.

$0.800(0.662 ; 0.885)$

6. This health professional talks with other health professionals to learn about the care received by my child.

$0.555(0.316 ; 0.729)$

7. This health professional makes contact with me when my child is cared for by other health professionals.

$0.688(0.465 ; 0.817)$

\section{About all health professionals involved in the care provided to the child in the last few months after discharge}

8. The health professionals who took care of my (my) child told me different things about the health of my child.

$0.408(0.125 ; 0.628)$

9. Someone explained to me the possible complications of my child's medical condition regarding his/her health status.

$0.217(-0.073 ; 0.476)$

10. Someone explained to me what treatments and tests were being performed on my (my) child and why.

$0.502(0.241 ; 0.694)$

11. Someone guided me about the exams, consultations and evaluations of my child.

$0.588(0.354 ; 0.752)$

12. The health professional who made the home visits to my child did not know his/her health history.

$0.308(-1.583 ; 0.934)$

13. The health professional who made the home visits to my child did not have access to information from the last assessment, visit or examination.

$0.500(-0.709 ; 0.983)$

14. I had to provide again information that I had already given about the health of my (my) child, which should have been included in the medical record.

$0.769(0.613 ; 0.867)$

15. I had to report the results of an appointment with a specialist to the health professional who was making a home visit to my child.

$0.893(0.210 ; 0.993)$

16. The health professionals who took care of my child gave all the guidance I needed to take care of him (her) at home.

$0.719(0.538 ; 0.837)$

17. The health professionals who took care of my child gave me all the guidance I needed to face minor problems or complications.

$0.490(0.235 ; 0.684)$

18. I had the impression that the health professionals who took care of my child knew him/her well.

$0.592(0.364 ; 0.753)$

19. When my child's health changed or worsened, I got answers or directions immediately.

$0.543(0.294 ; 0.752)$

20. The care offered to my child by the health system made me feel helpless.

$0.673(0.475 ; 0.807)$

Source: Research data, 2020. 


\section{DISCUSSION}

This study presented the process of cultural adaptation of the SpeNK-Q to Brazilian Portuguese based on the perspective of the authors of the instrument, that is, in order to promote the continuity of care for children with special health needs, it is essential to develop valid measures to assess the perceptions and experiences of parents when interacting with various services and professionals involved in the care of their children ${ }^{(3)}$. Moreover, the decision to culturally adapt an existing instrument instead of developing a new instrument was based on the justification of saving time and the possibility of comparing the results in different contexts as advantageous aspects of cultural adaptation ${ }^{(14)}$.

The steps recommended by the DISABKIDS ${ }^{\circledR}$ Group were observed in the cultural adaptation of the SpeNK-Q, and the same methodological rigor was used, which corroborates the relevant literature. After translation and back-translation of the instrument, the content validation process was initiated by a committee of experts. Regarding the composition of this committee of experts, the present study had ten judges, according to the criteria proposed in the literature for content validation, which considers a committee with a number ranging from six to twenty judges to be adequate ${ }^{(16)}$.

Regarding the general impression of the instrument, in particular concerning possible difficulties in using the Likert-type scale, most (88\%) of the participants reported that they had no difficulty in understanding the instrument. This positive perception by the participants contrasts with the perspective of a study that compared the visual analogue scale with the Likert-type scale and concluded that the Likert-type scale causes more interpretation problems ${ }^{(17)}$.

In the specific analysis of the semantic evaluation, the participants explained the items in their subset in their own words. Ten (83.3\%) mothers with secondary education correctly explained all the items in their subset and 11 (91.6\%) mothers with higher education also understood all items, indicating that the culturally adapted version for Brazilian Portuguese was easily understood by both groups. This result is consistent with the conclusions of the original authors of the instrument, who pointed out that the SpeNK-Q was well accepted and easily applied in the Italian population ${ }^{(3)}$. However, in the present study, the time taken to administer the adapted version was approximately 20 minutes, while in the original study, the parents filled the questionnaire in about ten minutes ${ }^{(3)}$. Such disagreement can be justified by the fact that the participants were not used to participating in surveys.

The importance attributed to each item was also observed in the specific analysis and the items referring to home visits by health professionals $(12,13,14$ and 15) were considered "not important" for mothers with higher education. For this purpose, the answer option "not applicable" was included for these items. Furthermore, in the pilot test stage, 74 (83\%) of the participants in the test stage and 38 (86\%) of the participants in the retest stage chose the "not applicable" answer option. Thus, this discussion is based on the perspective that home visits were not perceived as a follow-up strategy by the families, although the literature reiterates the benefits of home visits in promoting the strengthening of the bonds between health professionals and the families and consequently, ensuring continuity of care ${ }^{(2,9)}$.

A hypothesis that may explain the devaluation of home visits is that the majority (82\%) of the mothers answered that they had a health insurance plan and only a small portion of the participants (18\%) made exclusive use of the Unified Health System (SUS). In Italy, the country of origin of the SpeNK-Q, home visits are part of the health care provided by the "family pediatrician" for the entire population ${ }^{(10)}$.

Due to the COVID-19 pandemic, the pilot test stage (test and retest) was publicized by social media and data collection took place remotely. Such adaptation corroborates a recently published international study that aimed to present the adaptations in data collection strategies in qualitative and quantitative research, due to the pandemic situation. According to the authors, social media is an essential tool for establishing connections and sharing information, and the use of electronic forms is viable, safe and very convenient, considering social restrictions ${ }^{(8)}$.

There were 89 participants in the pilot test stage and 44 in the retest stage, and all were mothers. The mean age of these mothers was 32.49 years, minimum 20 and maximum 43 years, a result similar to the Italian study that was the origin of the SpeNK-Q in which the average age of mothers was 34.2 , minimum 18 and maximum 51 years ${ }^{(3)}$. Regarding the 95 preterm infants, the mean gestational age at birth was 30.4 weeks, corroborating the results of the study that was the origin of the SpeNK-Q, where the mean age was 30.1 weeks ${ }^{(2)}$. The average length of stay in a NICU was 51 days, an aspect that reinforces the role of technological advances in health in the survival of preterm infants ${ }^{(4,6)}$.

The adapted version of the SpeNK-Q had an internal consistency coefficient greater than 0.70 for all five factors, indicating high reliability. In the original version, Cronbach's a values were adequate $(>0.70)$ for four factors, except for factor 4 "family support" $(0.63)^{(3)}$. The same instrument has also been culturally adapted to the Chinese language based on interviews with 424 parents of preterm babies, and reliability analysis showed that the Cronbach's a coefficients of the factors ranged from 0.797 to $0.916^{(12)}$. 
In the present study, the strategy of reapplication of the instrument after 15 days (test-retest) was adopted in order to assess the reliability of the adapted version. However, the original study does not contain such information for comparison. According to the authors, this is a limitation of the study and they explained that they decided not to apply the same instrument twice, as this could be inconvenient for the parents who were experiencing a delicate situation related to the care of their children ${ }^{(3)}$.

The Chinese study also reapplied the instrument and obtained an ICC between 0.769 and 0.962 , that is, high reliability in all items ${ }^{(12)}$. On the other hand, in the present investigation, items 08 and 12 showed poor reliability with an ICC of 0.217 and 0.308 , respectively. A possible justification for this result is that both items refer to all health professionals involved in childcare in the last months after discharge, and not to a specific professional. This amplitude can cause different perceptions in parents depending on the health professionals they refer to in their responses to SpeNK-Q.

Finally, although the inexistence of a specific instrument for this purpose in Brazil was emphasized in the introduction of this study, it is important to highlight the use of the Primary Care Assessment Tool (PCATool-Brasil) instrument to analyze Primary Health Care services for CSHCN, through indirect analysis of the continuity of care. In this regard, it is worth mentioning a study with 55 caregivers of children with type 1 diabetes mellitus, which aimed to evaluate and compare the quality of primary care offered to these children ${ }^{(19)}$. According to the referred study, caregivers reported greater attachment to specialized services, which have difficulties of access and little coordination with other services, impacting the continuity of care in the network. By presenting the PCATool-Brasil as a possible tool for indirect analysis of the continuity of care, the study raises the possibility of future investigations that analyze the convergent validity of the SpeNK-Q.

\section{$\square$ CONCLUSION}

The present study aimed to evaluate the reliability of the adapted version of the SpeNK-Q for Brazilian Portuguese, and it was concluded that the results reached the expected objective. The study suggests adequacy of the SpeNK-Q regarding reliability, as the adapted version showed high internal consistency for all factors and there was moderate or strong test-retest reliability for most items.

One limitation of this study is the fact that the participants were only mothers of preterm newborns discharged from the NICU, most of them with higher education and medical insurance. So, further studies should include parents' perceptions, and contemplate parents and/or guardians that use public health services and have lower educational level. Another limitation concerns the online application of the SpeNK-Q, as although the original instrument was developed to be self-applied, the authors of the instrument indicate in the initial guidelines that the researcher can help parents to fill it out,

Finally, it is recommended that health professionals use the SpeNK-Q to support their practice, as this instrument can identify the fragmentation and discontinuity of care received by CSHCN and their families in a systematic and reliable way and, consequently, promote integrated and continuous assistance.

\section{REFERENCES}

1. McPherson M, Arango P, Fox H, Lauver C, McManus M, Newacheck PW, et al. A new definition of Children with Special Health Care Needs [comment]. Pediatrics. 1998;102(1):137-40. doi: https://doi.org/10.1542/peds.102.1.137

2. Neves ET, Okido ACC, Buboltz FL, Santos RP, Lima RAG. Accessibility of children with special health needs to the health care network. Rev Bras Enferm. 2019;72(Suppl 3):65-71. doi: https://doi.org/10.1590/0034-7167-2017-0899

3. Rucci P, Latour J, Zanello E, Calugi S, Vandini S, Faldella G, et al. Measuring parents' perspective on continuity of care in children with special health care needs. Int J Integr Care. 2015;15(4):e046. doi: http://doi.org/10.5334/ijic.2202

4. Frey HA, Klebanoff MA. The epidemiology, etiology, and costs of preterm birth. Semin Fetal Neonatal Med. 2016;21(2):68-73. doi: https://doi.org/10.1016/j. siny.2015.12.011

5. Braga PP, Sena RR. Becoming a caregiver of premature newborns and the devices part of the continuity of post-discharge care. Texto Contexto Enferm. 2017;26(3):e3070016. doi: https://doi.org/10.1590/0104-07072017003070016

6. Granero-Molina J, Medina IMF, Fernández-Sola C, Hernández-Padilla JM, Lasserrotte MDMJ, Rodríguez MDML. Experiences of mothers of extremely preterm infants after hospital discharge. J Pediatr Nurs. 2019;5:e2-e8. doi: https://doi.org/10.1016/j. pedn.2018.12.003

7. Fowler C, Green J, Elliott D, Petty J, Whiting L. The forgotten mothers of extremely preterm babies: a qualitative study. J Clin Nurs. 2019;28(11-12):2124-34. doi: https://doi.org/10.1111/jocn.14820

8. Nascimento ML, Pieszak GM, Arrué AM, Carvalho SORM. Children discharged from neonatal intensive care: implications for the social care networks. Rev Rene. 2016;17(5):707-15. doi: https://doi.org/10.15253/2175-6783.2016000500017

9. Berres R, Baggio MA. (Dis)continuation of care of the pre-term newborn at the border. Rev Bras Enferm. 2020; 3(3):20180827. doi: https://doi. org/10.1590/0034-7167-2018-0827

10. Zanelo E, Calugi S, Rucci P, Pieri G, Vandini S, Faldella G, et al. Continuity of care in children with special healthcare needs: a qualitative study of family's perspectives. Ital J Pediatr. 2015;41:7. doi: https://doi.org/10.1186/s13052-015-0114-x

11. Aires LCP, Santos EKA, Bruggemann OM, Backes MTS, Costa R. Reference and counter-reference health care system of infant discharged from neonatal unit: perceptions of primary care health professionals. Esc Anna Nery. 2017 [cited 2020 0ct 15];21(2):e20170028. Available from: http://www.scielo.br/j/ean/a/ g3L54ypryzYyJNvPZzzVrkJ/?lang=en 
12. Xiaojuan S, Xiaofang Q, Guihua L, Pin G, Yangin X, Minyan Y. [Evaluation of the reliability and validity of Chinese version Special Needs Kids Questionnaire (SpeNK-Q) in parents of preterm infants] [abstract]. J Nurs Sci. 2018 [cited 2020 Oct 18];(4):12. Chinese. Available from: http://en.cnki.com.cn/Article_en/ CJFDTotal-HLXZ201804012.htm

13. Disabkids ${ }^{\circledR}$ Group. Translation and validation procedure: guidelines and documentation form. Leiden: The DISABKIDS ${ }^{\circledR}$ Group; 2004.

14. Andrade RC, Leite ACAB, Alvarenga WA, Martimiano RR, Santos CB, Nascimento LC. Translation and cultural adaptation of the Needs of Parents Questionnaire (NPQ) to be used in Brazil. Esc Anna Nery. 2018;22(1):e20170104. doi: https:// doi.org/10.1590/2177-9465-ean-2017-0104

15. Trevethan R. Intraclass correlation coefficients: clearing the air, extending some cautions, and making some requests. Health Serv Outcomes Res Methodol. 2017;17(2):127-43. doi: https://doi.org/10.1007/s10742-016-0156-6

\section{- Acknowledgments:}

To the Coordination for the Improvement of Higher Education Personnel (CAPES) for the financial support for publication and to the Foundation for Research Support of the State of São Paulo (FAPESP) for the granting of a Scientific Initiation scholarship.

\section{- Authorship contribution:}

Conceptualization: Larissa Tassim Luciano Ferreira, Aline Cristiane Cavicchioli Okido.

Formal analysis: Larissa Tassim Luciano Ferreira, Patrícia

Casale Parra, Aline Cristiane Cavicchioli Okido.

Investigation: Larissa Tassim Luciano Ferreira, Patrícia

Casale Parra, Aline Cristiane Cavicchioli Okido.

Methodology: Larissa Tassim Luciano Ferreira, Patrícia

Casale Parra, Aline Cristiane Cavicchioli Okido.

Writing - original draft: Larissa Tassim Luciano Ferreira,

Patrícia Casale Parra, Aline Cristiane Cavicchioli Okido.

Writing - review and editing: Aline Cristiane Cavicchioli

Okido.

The authors declare that there is no conflict of interest.
16. Foth T, Efstathiou N, Vanderspank-Wright B, Ufholz LA, Dütthorn N, Zimansky $M$, et al. The use of Delphi and Nominal Group Technique in nursing education: a review. Int J Nurs Stud. 2016;60:112-20. doi: https://doi.org/10.1016/j. ijnurstu.2016.04.015

17. Voutilainen A, PitkäahoT, KvistT, Vehviläinen-Julkunen K. How to ask about patient satisfaction? the visual analogue scale is less vulnerable to confounding factors and ceiling effect than a symmetric Likert scale. J Adv Nurs. 2016;72(4):946-57. doi: https://doi.org/10.1111/jan.12875

18. Torrentira M. Online data collection as adaptation in conducting quantitative and qualitative research during the COVID-19 pandemic. Eur J Educ Stud. 2020;7(11):7887. doi: https://doi.org/10.46827/ejes.v7i11.3336

19. Wolkers PCB, Macedo JCB, Rodrigues CM, Furtado MCC, Mello DF. Primary care for children with type 1 diabetes mellitus: caregiver perspectives. Acta Paul Enferm. 2017;30(5):451-7. doi: https://doi.org/10.1590/1982-0194201700066

\section{- Corresponding author:}

Aline Cristiane Cavicchioli Okido

E-mail: alineokido@ufscar.br

\section{Associate editor:}

Wiliam Wegner 